\title{
Parent attitudes on the supply of alcohol to minors
}

\author{
Kypros Kypri PhD*1,2 \\ Johanna I Dean MSc ${ }^{3}$ \\ Elizabeth Stojanovski $\mathrm{PhD}^{1}$ ${ }^{2}$ Injury Prevention Research Unit, University of Otago, New Zealand ${ }^{3}$ Research Psychologist, Newcastle, Australia \\ ${ }^{1}$ School of Medicine and Public Health, University of Newcastle, Australia
}

\footnotetext{
* Author to whom correspondence should be addressed c/o 2 Edison St, Adamstown Heights NSW 2289 Australia

kypri@tpg.com.au Tel: +6124927 5957 Fax: +61 249246208
}

Word count: 3009 (Abstract: 216)

31 March 2006 


\begin{abstract}
Background: Inappropriate supply of alcohol by parents is often cited as a cause of teenage hazardous drinking. We investigated parental attitudes regarding supply of alcohol to minors, in a country which recently increased alcohol availability and where drinking per se is not prohibited at any age. Methods: Postal survey of 748 parents of 13-17 year-olds ( $80 \%$ response) in three New Zealand communities. Parents indicated agreement/disagreement with statements concerning teenage drinking and sources of alcohol, and described factors they considered in deciding whether to supply alcohol. Results: Four in five parents disagreed with permissive statements such as "It's okay for parents to give their teenager one or two drinks to take to an unsupervised party", and 59\% agreed that "No one should supply alcohol to someone who is underage". Recent suppliers commonly said they would only supply if there was suitable adult supervision at the drinking location. Many said they would only supply at home with a meal and reported restrictions on quantity and strength, e.g., "no spirits or mixed drinks", "small quantity only". Conclusions: Parents generally opposed supply to minors or they specified responsible conditions of supply. They favoured legal restrictions on availability and promotion, and greater enforcement of liquor laws. The findings should be interpreted in light of social desirability bias and limitations of generalisability outside the participating communities.
\end{abstract}

Keywords: alcohol, minors, underage, supply, parents 


\section{Introduction}

In several industrialized countries, including New Zealand, drinking to intoxication has become the predominant alcohol consumption pattern among 12-19 year-olds. For example, in a study of secondary school students in 29 European countries, $39 \%$ of reported drinking episodes involved consumption of more than five drinks [1]. There was considerable inter-country variation, with a north-south gradient: in Iceland, 88\% of drinking episodes were reported to result in intoxication, while in Cyprus, the figure was $6 \%$.

In US schools, approximately $20 \%$ of $13-14$ year-olds and almost $50 \%$ of 17 18 year-olds reported consuming five or more drinks in one occasion during the past month [2]. Among New Zealand 16-17 year-olds, approximately 25\% of males reported weekly consumption of six or more drinks, while $22 \%$ of females reported weekly consumption of four or more drinks in 2000 [3].

Laws and social mores pertaining to the supply of alcohol vary considerably from place to place. In the USA, by 1988 all 50 states had adopted a so-called minimum legal drinking age, in which the sale of alcohol to a person under age 21 , and possession by a minor, is illegal. Notably, however, 13 states do not prohibit attempts to purchase by minors and 14 states do not prohibit consumption of alcohol per se, such that there is effectively a gradient of drinking age laws within the USA [4]. Other industrialised countries have more liberal youth drinking laws. For example, the United Kingdom, most other European countries, and Australia, for several decades, have had laws prohibiting the purchase of alcohol by persons aged below 18 years, but not consumption per se.

In 1999, New Zealand became the first jurisdiction in 25 years, anywhere in the world, to reduce the minimum purchase age (from 20 to 18 years). There is 
evidence that this law change increased the incidence of traffic crash injuries related to drink-driving in the target age group (18-19 years) but also relating to $15-17$ yearold drivers, a so-called ‘trickle down' effect [5].

Under New Zealand law, access to alcohol is subject to provisions of the Sale of Liquor Act (1989) and the Sale of Liquor Amendment Act (1999). These laws do not proscribe alcohol consumption per se. Minors may consume alcohol in private settings and parents are not prohibited from giving their children alcohol. The law prohibits adults from supplying minors other than their children with alcohol, with an important exception which permits adults to provide alcohol to persons of any age in a 'private party', which is not defined in either Act.

Parents have frequently been cited as a primary source of inappropriate supply of alcohol to minors $[6,7]$, although the evidence base for this claim is limited. In a sample of 872 15-17 year-olds from three New Zealand communities on which the present study was based, $67 \%$ said that in the last four weeks they had obtained alcohol from parents, $57 \%$ from friends, while $16 \%$ purchased from a liquor store and $11 \%$ from a pub or bar [8]. However, the contribution of these various sources of alcohol to heavy episodic drinking in this age group remains unclear. For example, it is possible that teenagers obtain relatively small quantities of alcohol from parents, e.g., a glass of wine at dinner, one or two beers (10-30 g ethanol) to take to a party. Larger quantities may be obtained from friends or when making an illegal purchase, e.g., a six-pack of beer (60-90 g ethanol) or pre-mixed spirits (80-120 g ethanol). Further research is needed to clarify this issue.

Because of the concern about teenage hazardous drinking, the Alcohol Advisory Council - the lead government agency on alcohol in New Zealand - trialled a campaign in partnership with two South Island communities, namely, the districts of 
Ashburton and Waitaki. The aims of that campaign were to reduce illegal retail sales to minors, illegal supply by other adults, and risky (but legal) supply by adults, including supply by parents to their children for unsupervised drinking (hereafter referred to as SUD). In 2001, a community action campaign was mounted, including as its centrepiece, social marketing of the risks of illegal supply and inappropriate provision.

An evaluation of that campaign was undertaken with a quasi-experimental design, in which a demographically similar district where the campaign was not implemented (Clutha), acted as a comparison community. At baseline, $36 \%$ of teenagers across the three communities reported that their parent(s) had given them alcohol to drink in an unsupervised setting in the preceding month. In contrast, only $2 \%$ of parents said they had given their child alcohol to drink in an unsupervised setting [8].

Analysis of teenagers' reports of parental SUD revealed non-significant reductions in SUD over the course of the campaign. Notably, however, the 2-week prevalence of binge drinking did not change in the expected direction, leading to the conclusion that parental supply and teenage binge drinking may not be causally linked in the way some have assumed them to be. In addition to being asked about their recent supply behaviours, parents were asked a number of questions about their attitudes on the subject of supply. The purpose of this study was to utilise this quantitative and qualitative information to investigate parental attitudes regarding supply of alcohol to minors.

\section{Methods}


The data used in this study were collected as part of an evaluation of a community prevention campaign (see [8]). The computation of sample sizes, questionnaire development, and data collection procedures have been described in detail elsewhere $[8,9]$. In summary, all seven of the high schools in the districts of Ashburton (population 25,446), Waitaki $(20,088)$, and Clutha $(17,172)$ participated by providing access to a random selection of classrooms for surveying teenagers, and a list of postal addresses for all parents with students at the schools.

Random samples of households were selected from the enrolment lists of the seven schools. Only parents who resided in the district were eligible for selection. Each household received only one parent questionnaire irrespective of the number of teenagers residing there. All sampled households received a letter in late July 2001, along with a questionnaire and a stamped return envelope. The letter informed potential participants that their responses would be confidential, that only statistical summary data would be reported, and that contact details would be stored separately from completed questionnaires. The parent with the next birthday was asked to complete the questionnaire. Entry in a prize draw was offered as an incentive to participate. Trained interviewers (all with postgraduate qualifications in psychology) telephoned non-respondents to request return of the survey forms and to offer the option of a telephone interview.

The Parent Alcohol Survey was a two-page questionnaire which was pretested with parents in the study communities. It requested the respondent's demographic data (gender, age, ethnicity) and their teenager's demographic data. Respondents were then presented with a list of 10 statements (presented in Table 1) and were asked to indicate the extent of their agreement/disagreement on a five-point scale. 
Parents were asked "At what age do you think it is appropriate for a person to start drinking (i.e. more than a sip)?" and to indicate how often they supplied alcohol to their teenager and other teenagers in the preceding four weeks. Parents were invited to provide written comments concerning the supply of alcohol to their own teenagers and other teenagers.

The free text comments were reviewed and a 21-point coding system was developed. A random sample of $10 \%$ of the comments was independently coded by two of the authors (JD and LS), and a Kappa statistic was calculated as a measure of inter-rater reliability [10]. Once acceptable inter-rater reliability was achieved, all of the comments were coded by one author (LS) and were summarised in terms of the conditions in which parents indicated they would supply alcohol to their teenager, and a teenager other than their own.

\section{Results}

Of the 972 households sent questionnaires, in 25 cases, the selected parent was subsequently deemed ineligible to participate because the family had moved out of the area or there was no longer anyone under 18 years of age in the household. Completed forms were received from 756 parents, of whom eight were deemed ineligible because their response was based on a person of the legal minimum purchase age (i.e., 18 years). The remaining 748 responses represent $80 \%$ of the forms sent to eligible households. Of these, 660 (88\%) were self-completed and returned by post and 88 $(12 \%)$ by telephone interview. Two thirds $(66 \%)$ of the respondents were women and the mean age was 43 years. Ethnicities represented were New Zealand European (88\%), Māori (5\%), Chinese (1\%), Indian (0.3\%), and Other (6\%). 


\section{Survey item responses}

Table 1 summarises the parents' responses to the 10 statements. For items 2-8, which may be broadly described as permissive statements about teenage drinking or societal attitudes toward it, 71-98\% of parents disagreed or strongly disagreed with the statements. Similarly, for item 1, a restrictive statement, 77\% agreed or strongly agreed. Most parents (59\%) agreed with the categorical statement expressed in item 9, that "No one should supply alcohol to someone who is under age". Responses to item 10 show that two thirds of parents opposed the lowering of the minimum purchase age which had occurred in 1999.

Pearson chi-squared tests were conducted to examine differences by parent gender, in the distribution of responses to each of the statements. After Bonferroni adjustment for multiple tests $(0.05 / 10)$, for two of the responses there were statistically significant differences between male and female parents/caregivers. A greater proportion of men than women (11\% versus $4 \%)$ tended to agree that "There's no point in trying to stop your teen from getting drunk occasionally", while a greater proportion of women than men (62\% versus $55 \%)$ agreed that "No one should supply alcohol to someone who is under age".

$<$ Table 1 $>$

Figure 1 shows the distribution of responses regarding parents' views of the appropriate age for people to start drinking alcohol ("more than a sip"). The modal response was 18 years $(26.7 \%)$, which was the minimum purchase age at the time of the survey. One in five $(20.5 \%)$ said 16 years, and $15.0 \%$ said 20 years, the minimum legal purchase age prior to December 1999. It should be noted that $9 \%$ of respondents 
did not give an age: $43(5.7 \%)$ wrote a comment to the effect they were unsure, while $26(3.5 \%)$ did not answer the question. Of the remaining 679 respondents, the mean age given was 17.2 years $(\mathrm{SD}=2.1)$.

$<$ Figure 1 $>$

Free-text comments concerning circumstances of parental supply of alcohol

In 304 cases ( $41 \%$ of all respondents), parents made comments regarding factors they considered when deciding whether or not to supply their teenager and/or another teenager with alcohol. Thirty questionnaires (10\%) containing text responses to either of these items were randomly selected for independent classification by two of the authors. There was $93 \%$ agreement ( $95 \%$ confidence interval: $84 \%$ to $100 \%$ ) between coders on all open-ended responses in these surveys, i.e., the true agreement rate was at least $84 \%$ with $95 \%$ confidence [10]. The coding scheme and manual are available upon request.

Parents made comments regarding factors they considered when deciding whether or not to supply their teenager with alcohol in 283 cases (38\%). Table 2 summarises the 283 respondents' comments according to the coding scheme. The most commonly cited condition of supply which parents mentioned was adult supervision ( $\mathrm{n}=164,58 \%$ of those who made comments mentioned this). This category comprised two subgroups: persons who specified that the adult had to be the teenager's parent $(n=73)$, and persons who did not $(n=91)$. The next largest categories were volume and strength $(\mathrm{n}=110,39 \%)$, and drinking location/occasion $(\mathrm{n}=88$, $31 \%$ ). Typical comments in each of these large categories were "must be with 
parents", "I would not give them spirits or mixed drinks", and "must be a special occasion”, respectively.

$<$ Table 2>

In 200 cases $(27 \%)$, parents made comments regarding factors they would consider if supplying a teenager other than their own, with alcohol. A summary of these is presented in Table 3. The most commonly cited factors were consent of the teenager's parent $(\mathrm{n}=79,40 \%)$, supervision by an adult and/or the teenager's parent $(\mathrm{n}=41$, $21 \%)$, and limits on volume and strength $(\mathrm{n}=22,11 \%)$. Typical comments in each of these large categories were, "would not supply another teen with alcohol without parent permission", "in a group situation with friends of my son and parents present" or "I would have to be there to supervise", and "would inform parents if I was intending on supplying small-medium amount of alcohol to teenager", respectively.

\section{Discussion}

A large majority of parents opposed permissive statements concerning supply and promotion of alcohol to teenagers, and endorsed restrictive statements. For example, $81 \%$ disagreed that "It's okay for parents to give their teenager one or two drinks to take to an unsupervised party", and 59\% agreed that "No one should supply alcohol to someone who is underage". Recent suppliers commonly said they would only supply if there was suitable adult supervision at the drinking location, and many stipulated that the supervisor had to be the teenager's parent. Many said they would only supply at home with a meal, or for a special celebration, and reported restrictions on the quantity and strength of the alcohol they would provide, e.g., "no spirits or mixed 
drinks", "small quantity only". Views about when people should start drinking were more varied: with a modal response of 18 , and large proportions of respondents saying 16 or 20 .

Many of the parents who reported recently supplying their children with alcohol, gave reasoned arguments for doing so. The most common of these was "teen joining parents for a drink with a meal or for a special celebration". A similar result was obtained for parents who commented on conditions in which they would supply a teenager who was not their own.

There are some apparent inconsistencies in the response by parents in the attitudes data and the data concerning the appropriate age for people to start drinking. Two thirds of respondents disagreed with the lowering of the minimum purchase age to 18 (Table 1), yet a majority believed that an appropriate age to start drinking was 18 or younger (Figure 1). This may reflect the belief, expressed in the free-text comments elicited in this study, that giving minors small quantities of alcohol to be consumed under parental supervision is a sensible way to model moderate drinking.

The study has a number of limitations. Principal among these is the likelihood of social desirability bias. Although confidentiality was guaranteed, and identifying information was not requested on the questionnaire, the survey was not anonymous. It is therefore likely that some parents adjusted their responses to fit with what they believed would be socially desirable, presumably, understating their support for permissive sentiment, and favouring restrictive statements and conditions of supply. Evidence of this is the difference in reporting of SUD between parents and teenagers 
in the earlier study of this population [8]: $36 \%$ of teenagers said their parents had given them alcohol to drink without supervision, while only $2 \%$ of parents reported doing this. While it is likely the difference in reporting is overstated, due, in part, to possible differences in interpretation of the questions (discussed in [8]), there is probably still a discrepancy attributable to socially desirable response by parents, and it may have influenced the results presented here.

Non-response bias is also a consideration. In the present study, the response from this random sample of parents was $80 \%$, although a further $8-10 \%$ of respondents did not complete some or all of the attitudes items and the question concerning the appropriate age to start drinking, some indicating they preferred not to do so. It is impossible to know the direction of any bias attributable to non-completion of these items, however, given that the overall response was still high, the effects are likely to be small [11].

There are also limitations in the generalisability of the findings outside the participating communities. The study populations are not representative of the entire New Zealand parent population. There are relatively small proportions of New Zealand Maori, Pacific, and Asian peoples in the study districts and these groups are known to have different drinking patterns to those of the New Zealand Europeans [1214]. In the year of the study, $14 \%$ of the New Zealand population self-identified as Maori, compared with only $5 \%$ of parents in the present study [15]. Of all households in New Zealand, 31\% are headed by one parent [15], however, census data do not provide a breakdown by sex of the parent. In this study, $66 \%$ of respondents were women. This may reflect the prevalence of one parent households headed by women, 
and possibly tendency of men to not participate, which is commonly observed in household surveys [16].

The districts involved in the study are also not typical of New Zealand in terms of alcohol policy. At the time of the survey, Ashburton district (an intervention site), was one of a few remaining areas in New Zealand to have a Liquor Licensing Trust, reflecting a historically more restrictive approach to alcohol in that community. This was manifested at the time of the study in the prohibition of alcohol sales in supermarkets, a rule which has since been revoked.

The findings have implications for policy and research. In March 2006, the Law and Order Select Committee of the New Zealand parliament began considering the Sale of Liquor (Youth Alcohol Harm Reduction) Amendment Bill, which includes provision for a minimum purchase age of 20 years. A central tenet of the liquor industry's argument for not increasing the minimum purchase age, is that parents supply most of the alcohol consumed by minors [17], yet the evidence for this claim is poor. The results of the present study, taken with those of the intervention study on which it is based [8], suggest that parents are generally responsible suppliers of alcohol. There is strong research evidence showing reductions in alcohol-related harm when availability is reduced via an increase in the minimum purchase/drinking age [18, 19], and the results of the present study suggest that such a change would be favoured by the majority of parents, at least in the districts studied.

There are alternative, indirect, conceptualisations of the relationship between parental supply of alcohol and teenage drinking. For example, by permitting supervised 
drinking at a young age, parents may unwittingly set in train a developmental process by which the progression to unsupervised drinking is made more rapidly than it would otherwise have been. Parental unwillingness to supply alcohol at ages $15-17$ years would not necessarily impact drinking behaviour (idea suggested by anonymous referee).

New Zealand scientific research on social supply to date, has failed to determine the quantities and context of supply. It is not known, for example, where minors obtain alcohol for drinking occasions which result in intoxication. It is possible, for example, that parents who supply, typically do so with small quantities, and that larger quantities are obtained via illegal purchases and from peers. A proposal in the bill presently being considered by the New Zealand parliament, is to prohibit supply of alcohol to minors, by anyone other than the minor's parent or legal guardian. This would substantially change the dynamics of alcohol availability to young people in New Zealand, and it is important that research is conducted to improve our understanding of the role of various sources of supply, including parents, irrespective of whether the law changes.

\section{Acknowledgements}

We are grateful to the Alcohol Advisory Council of New Zealand for funding the study, and for their contribution to the evaluation project on which the present study is based. We acknowledge two anonymous reviewers for helpful comments on a draft of the paper. 


\section{References}

1. Plant M, Miller P. Young people and alcohol: An international insight. Alcohol and Alcoholism 2001;36(6):513-5.

2. Johnston LD, O'Malley PM, Bachman JG. Monitoring the Future:

National Results on Adolescent Drug Use. Overview of Key Findings, 2002.

Bethesda, MD: National Institute on Drug Abuse; 2003.

3. Habgood R, Casswell S, Pledger M, Bhatta K. Drinking in New Zealand: National surveys comparison 1995 \& 2000. Auckland: Alcohol and Public Health Research Unit; 2001.

4. National Institute on Alcohol Abuse and Alcoholism. Underage Drinking Maps and Charts. National Institute on Alcohol Abuse and Alcoholism's Alcohol Policy Information System (APIS) Web site. Retrieved 28/02/06, from www.alcoholpolicy.niaaa.nih.gov/. In; 2006.

5. Kypri K, Voas RB, Langley JD, Stephenson SCR, Begg DJ, Tippetts AS, et al. The minimum purchase age for alcohol and traffic crash injuries among 15-19 year-olds in New Zealand. American Journal of Public Health 2006;96(1):126-131.

6. de Bonnaire C, Kalafatelis E, Whitfield J, Harsant M. Youth and Alcohol: ALAC Youth Drinking Monitor. Wellington: BRC Marketing \& Social Research; 2000.

7. Tutt D. "I'd rather they were drinking where I can see them..."; Teenage alcohol consumption promoted by adults. In: Winter School in the Sun; 2003; Brisbane; 2003.

8. Kypri K, Dean JI, Kirby S, Harris J, Kake T. Think before you buy under-18s drink: Evaluation of a community alcohol intervention. Drug and Alcohol Review 2005;24(1):13-20.

9. Kypri K, Dean JI. The Should You Supply community alcohol intervention: An evaluation for the Alcohol Advisory Council of New Zealand. Occasional Publication. Wellington: ALAC; 2002 January. Report No.: 14 .

10. Nunnally JC. Psychometric theory. 2d ed. New York: McGraw-Hill; 1978.

11. Caetano R. Non-response in alcohol and drug surveys: a research topic in need of further attention. Addiction 2001;96(11):1541-5.

12. Bramley DM, Broad JB, Harris R, Reid M-JP, Jackson R. Differences in patterns of alcohol consumption between Mäori and non-Mäori in Aotearoa (New Zealand). New Zealand Medical Journal 2003;116(1184).

13. Huakau J, Asiasiga L, Ford M, Pledger M, Casswell S, Suaalii-Sauni T, et al. New Zealand Pacific peoples' drinking style: too much or nothing at all? N Z Med J 2005;118(1216):U1491.

14. Kypri K, Stephenson SCR, Langley J. Episode-centred analysis of drinking to intoxication in university students. Alcohol \& Alcoholism 2005;40(5):447-452.

15. Statistics New Zealand. Demographic Trends. Wellington: Statistics New Zealand; 2001. 
16. Dillman DA. Mail and internet surveys : the tailored design method. 2nd ed. New York: J. Wiley; 2000.

17. Stewart N. Parliamentary Paper - Alcohol: Let's Look at the Facts not the Fiction. Wellington: Beer Wine and Spirits Council of New Zealand; 2005. 18. Shults RA, Elder RW, Sleet DA, Nichols JL, Alao MO, Carande-Kulis VG, et al. Reviews of evidence regarding interventions to reduce alcoholimpaired driving. American Journal of Preventive Medicine 2001;21(4 Suppl. 1):66-88.

19. Wagenaar AC, Toomey TL. Effects of minimum drinking age laws: Review and analyses of the literature from 1960 to 2000. Journal of Studies on Alcohol 2002;Suppl14:206-225. 
Table 1. Parent attitudes to teenage drinking and issues of supply (\%)*

\begin{tabular}{|c|c|c|c|c|c|c|c|}
\hline & & $\begin{array}{l}\text { Strongly } \\
\text { agree }\end{array}$ & Agree & $\begin{array}{l}\text { Neither } \\
\text { agree or } \\
\text { disagree }\end{array}$ & Disagree & $\begin{array}{l}\text { Strongly } \\
\text { disagree }\end{array}$ & $\begin{array}{c}\text { P-value for } \\
\text { Pearson chi } \\
\text { square test of } \\
\text { difference by } \\
\text { gender }\end{array}$ \\
\hline (1) & $\begin{array}{l}\text { It's better for a parent/caregiver to } \\
\text { give their teen alcohol than for the } \\
\text { teen to obtain it illegally }\end{array}$ & 32 & 45 & 12 & 6 & 5 & 0.945 \\
\hline (2) & $\begin{array}{l}\text { Teenagers quickly learn to make } \\
\text { responsible decisions about drinking } \\
\text { alcohol }\end{array}$ & 1 & 15 & 15 & 49 & 22 & 0.053 \\
\hline (3) & $\begin{array}{l}\text { You just have to let your teenager } \\
\text { learn for themselves about drinking }\end{array}$ & 1 & 9 & 6 & 43 & 42 & 0.049 \\
\hline (4) & $\begin{array}{l}\text { It's okay for parents to give their } \\
\text { teenager(s) one or two drinks to take } \\
\text { to an unsupervised party }\end{array}$ & 1 & 12 & 7 & 42 & 39 & 0.418 \\
\hline (5) & $\begin{array}{l}\text { There's no point in trying to stop your } \\
\text { teen from getting drunk occasionally }\end{array}$ & 0 & 7 & 5 & 43 & 46 & $0.001^{a}$ \\
\hline (6) & $\begin{array}{l}\text { It's okay for teenagers to get drunk at } \\
\text { the weekend }\end{array}$ & 0 & 0 & 2 & 29 & 69 & 0.467 \\
\hline (7) & $\begin{array}{l}\text { It's too late to control my teenager's } \\
\text { drinking }\end{array}$ & 0 & 1 & 3 & 32 & 65 & 0.122 \\
\hline (8) & $\begin{array}{l}\text { The media exaggerates problems } \\
\text { due to teenage drinking }\end{array}$ & 2 & 12 & 12 & 47 & 28 & 0.015 \\
\hline (9) & $\begin{array}{l}\text { No one should supply alcohol to } \\
\text { someone who is under age }\end{array}$ & 37 & 22 & 15 & 23 & 4 & $0.001^{b}$ \\
\hline (10) & $\begin{array}{l}\text { It's good that the government } \\
\text { changed the law to allow } 18 \text { and } 19 \\
\text { year-olds to purchase alcohol }\end{array}$ & 2 & 19 & 11 & 28 & 39 & 0.285 \\
\hline
\end{tabular}

*Excludes cases with missing data and where respondent indicated they preferred not to answer, i.e, between 64 and 77 cases per item.

**With Bonferroni adjustment for multiple tests, p-level for statistical significance is 0.005

${ }^{a}$ Men more often agreed or strongly agreed with the statement

${ }^{\mathrm{b}}$ Women more often agreed or strongly agreed with the statement 
Table 2. Summary of parent free-text responses concerning conditions in which they would supply of alcohol to their teenager*

\begin{tabular}{|l|c|}
\hline \multicolumn{1}{|c|}{ Conditions of supply } & Number (\%) \\
\hline $\begin{array}{l}\text { Adult supervision } \\
\text { Respondent stipulated that they would have to have contact with adult hosts } \\
\text { prior to supplying their teen with alcohol: } 73 \text { of these specified that the adult } \\
\text { had to be the teenager's parent, and 91 did not specify. }\end{array}$ & 164 (59) \\
\hline $\begin{array}{l}\text { Volume and strength } \\
\text { Respondent indicated restrictions on quantity and/or strength of alcohol } \\
\text { they would supply }\end{array}$ & 110 (39) \\
\hline $\begin{array}{l}\text { Location/occasion } \\
\text { Respondent said they would only supply if they knew where their teenager } \\
\text { would be socialising and/or that the nature of the occasion was imporant }\end{array}$ & 88 (31) \\
\hline $\begin{array}{l}\text { Only at home } \\
\text { Respondent stipulated that they would only supply alcohol in the home } \\
\text { setting, usually with a meal or for a special celebration }\end{array}$ & 49 (17) \\
\hline $\begin{array}{l}\text { Maturity } \\
\text { Respondent stipulated that they would only supply alcohol if their teenager } \\
\text { was mature and trustworthy and had a responsible attitude to drinking }\end{array}$ & 31 (11) \\
\hline $\begin{array}{l}\text { Transport } \\
\text { Respondent said they would only supply if safe transport had been } \\
\text { arranged }\end{array}$ & 31 (11) \\
\hline $\begin{array}{l}\text { Friends } \\
\text { Respondent said they would only supply if they knew with whom their } \\
\text { teenager would be socialising }\end{array}$ & 24 (8) \\
\hline $\begin{array}{l}\text { Age } \\
\text { The age of their teenager was a key consideration in deciding whether or } \\
\text { not to supply alcohol }\end{array}$ & 21 (7) \\
\hline $\begin{array}{l}\text { Other conditions ( } \boldsymbol{n}<10 \text { ) } \\
\text { A variety of other conditions were mentioned, including: that alcohol not be } \\
\text { available from other sources, that it not be shared, that they would not } \\
\text { supply if they believed their teen would be subject to peer pressure, that } \\
\text { their teenager not be on medication, that food should be available. }\end{array}$ & 36 (13) \\
*Parents were responding to the following request: “If there are important factors you would consider \\
in deciding whether or not to provide your teenager with alcohol, please describe them here." \\
**Percent of all persons who made a comment in relation to the question (n=283); does not sum to \\
$\begin{array}{l}100 \% \text { because some respondents listed multiple conditions for supplying (n=556 comments altogether), } \\
\text { and each condition was coded separately. }\end{array}$ \\
\end{tabular}


Table 3. Summary of parent free-text responses concerning conditions in which they would supply alcohol to a teenager other than their own*

\begin{tabular}{|l|c|}
\hline \multicolumn{1}{|c|}{ Conditions of supply } & Number (\%)** \\
\hline $\begin{array}{l}\text { Parental consent } \\
\text { Respondent stipulated that they would have to have the consent of the } \\
\text { parent to supply the teen with alcohol }\end{array}$ & $79(40)$ \\
\hline $\begin{array}{l}\text { Supervision by adult or teenager's parent } \\
\text { Respondent indicated that there had to be supervision by and adult and/or } \\
\text { the teenager's parent }\end{array}$ & $41(21)$ \\
\hline $\begin{array}{l}\text { Volume and strength } \\
\text { Respondent indicated restrictions on quantity and/or strength of alcohol } \\
\text { they would supply. }\end{array}$ & $22(11)$ \\
\hline $\begin{array}{l}\text { Location } \\
\text { Respondent said they would only supply alcohol if they knew where the } \\
\text { teenager would be socialising. }\end{array}$ & $12(6)$ \\
\hline $\begin{array}{l}\text { Teenager well known to parent } \\
\text { Respondent stipulated that they would have to know the teenager well to } \\
\text { supply them with alcohol }\end{array}$ & $11(6)$ \\
\hline $\begin{array}{l}\text { Other conditions ( } \boldsymbol{n}<\mathbf{1 0}) \\
\text { A variety of other conditions were mentioned, including: the teenager had to } \\
\text { be staying overnight, if where they were going afterwards was appropriate, } \\
\text { only if the drinking was occurring in the parent's home, and if the teenager } \\
\text { was mature/trustworthy }\end{array}$ & $45(23)$ \\
\hline
\end{tabular}

*Parents were responding to the following request: "If there are important factors you would consider in deciding whether or not to provide a teenager other than your own with alcohol, please describe them here."

**Percent of all persons who made a comment relating to this question ( $\mathrm{n}=200)$; does not sum to $100 \%$ because some respondents listed multiple conditions for supplying alcohol ( $\mathrm{n}=210$ comments altogether), and each was coded separately. 


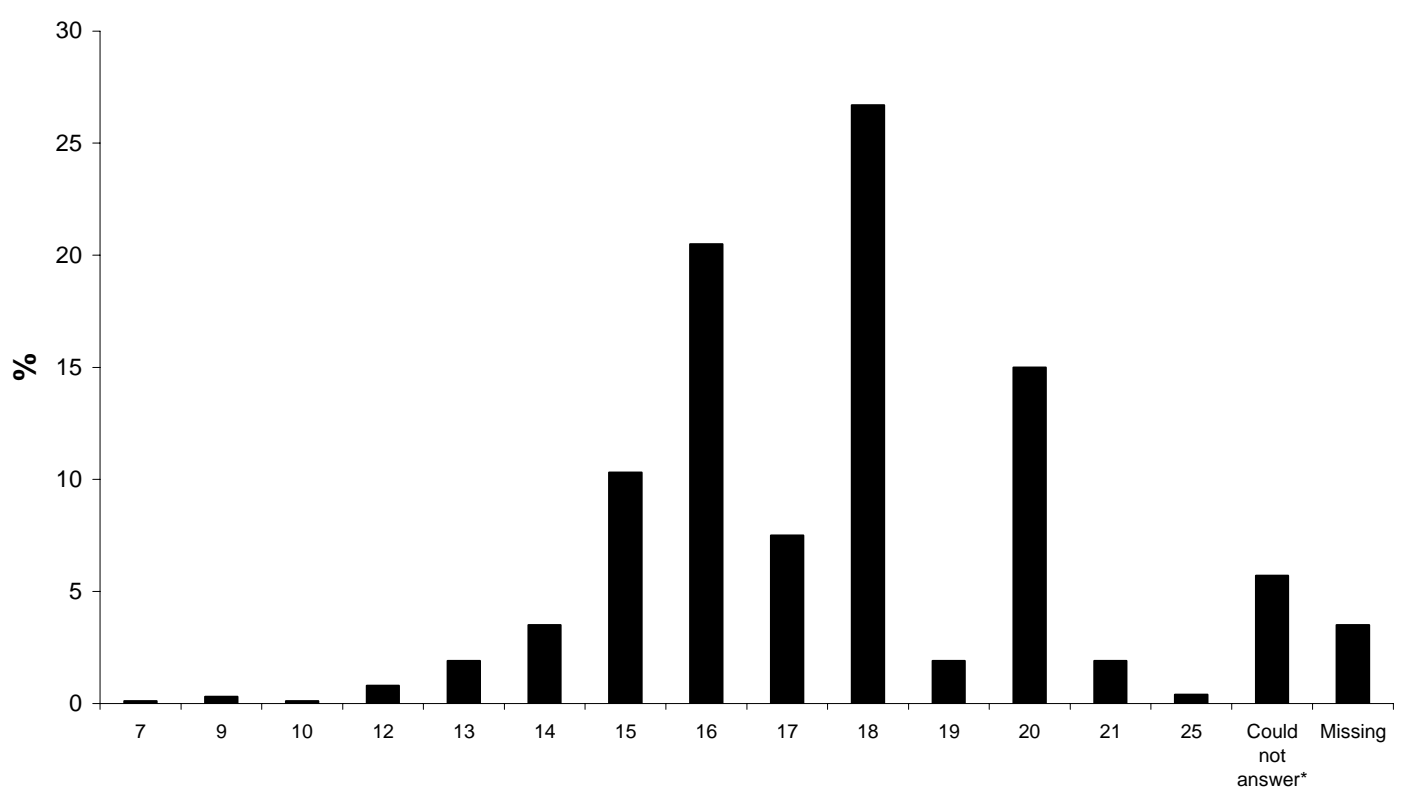

Age in years

*Coded from written comments or phone interviews

Figure 1. Parents" views of the appropriate age for a person to start drinking ("more than a sip") 